\title{
VIOLÊNCIA POLÍCIAL E A RESPONSABILIZAÇÃO INTERNACIONAL DO BRASIL NO CASO FAVELA NOVA BRASÍLIA
}

\author{
Rafaela Teixeira Sena Neves ${ }^{1}$ \\ Verena Holanda Mendonça Alves ${ }^{2}$
}

\section{RESUMO}

O objetivo deste trabalho consiste em analisar a impunidade em casos de violência estatal por meio do caso Favela Nova Brasília (2017), que expõe o problema da violência policial e seletividade penal, especialmente quanto às execuções extrajudiciais e a falta de responsabilização criminal. Assim, utilizando-se de um estudo doutrinário e jurisprudencial, procura-se verificar em que medida a polícia pode ser meio do exercício de uma prática de governança ou se caracterizaria como modelo de poder em si mesmo, a partir da análise crítica desse caso e de os institutos da "governança", "polícia" e sua relação com os Direitos Humanos.

Palavras-chaves: violência policial; Favela Nova Brasília; governança; responsabilidade internacional.

\section{POLICE BRUTALITY AND INTERNATIONAL RESPONSIBILITY OF BRAZIL IN THE CASE OF FAVELA NOVA BRASÍLIA}

\begin{abstract}
This paper aims to analyze the impunity in cases of State violence through the case of Favela Nova Brasília (2017), which exposes the problem of police violence and criminal selectivity in Brazil, especially regarding no judicial executions and the lack of criminal process. This essay, adopting a theoretical and empirical approach from the judgment of the Inter-American Court of Human Rights, it examines concepts of "governance", "policy" and it relationship with human rights to verify to what extent the police can be a means of exercising a governance practice or would be characterized as a model of power in itself.
\end{abstract}

\footnotetext{
${ }^{1}$ Doutoranda em Direito pela UFPA. Visiting scholar at Human Rights Institute of Columbia University in the City of New York (2019); Global Legal Studies of Wisconsin University (2018-2019); Forsythe Family Program on Human Rights and Humanitarian Affairs of University of Nebraska/Lincoln (2019); Universidad Iberoamericana Ciudad de México (2018); PUC RIO (2017) e na FGV SP (2017). Mestra em Direito pela UFPA (2016). Successfully attended in the Academy on Human Rights and Humanitarian Laws Program of Advanced Studies on Human Rights and Humanitarian Law of the American University Washington College of Law (2015). Pesquisadora Visitante da Corte Interamericana de Direitos Humanos (2015). Bacharela em Direito pelo CESUPA (2014). Advogada.

${ }^{2}$ Doutora em Direito Político e Econômico pela Universidade Presbiteriana Mackenzie, onde foi bolsista por colocação, frente aprovação em primeiro lugar na seleção de 02/2016. Mestre em Direitos Humanos pelo Programa de Pós-Graduação em Direto da Universidade Federal do Pará. Graduada em Direito pelo Centro Universitário da Pará - CESUPA. Professora da Faculdade Metropolitana da Amazônia - FAMAZ, onde leciona Direito Penal, Processo Penal, Prática Penal e Ética Profissional. Professora do Centro Universitário do Pará CESUPA, onde leciona Direito Penal. Pesquisadora no Grupo de Estudos e Pesquisas Direito Penal e Democracia. Membro do grupo de pesquisa Mulher, Sociedade e Direitos Humanos. Inscrita na OAB/PA sob o $\mathrm{n}^{\circ} 19043$.
} 
Key-words: Police brutality; Favela Nova Brasília case; international responsability; governance.

\section{INTRODUÇÃO}

Nas últimas décadas, as democracias do mundo vêm enfrentando o aumento exponencial de crimes violentos em seus territórios. Atrelado ao incremento numérico dos dados estatais penais, cresceu, também, a sensação de medo e de insegurança entre aqueles ocupantes destes territórios. Em parte pela mídia, tais notícias atraem a população para um intenso debate na área de políticas relacionadas à segurança pública, na qual a polícia se torna cada vez mais visível, discutida e politizada em resposta as pressões e lides direcionadas ao provimento de serviços de policiamento. Insurgem-se diversas opiniões voltadas a adequação, transformação e até extinção da policia nacional, sempre com a mesma justificativa: erradicar a tenebrosa criminalidade ou pelo menos controlar o crime.

No Brasil, mesmo após o advento da Constituição Federal de 1988 (considerada como marco democrático), não foi revertida à ordem, caracterizadora e militarizada que existia antes. Tal constatação pode ser verificada, entre outros motivos, pela forma como as instituições policiais ainda são consideradas como responsáveis por garantir a segurança pública do país, segundo o artigo 144 da mesma lei ${ }^{3}$. Frente o reducionismo com o qual a segurança pública foi tratada no texto constitucional, é possível inferir que quem governa a polícia também acaba governando a segurança pública nacional.

A gestão do medo da população em geral, o incremento do sentimento de insegurança social e a crença de que quanto mais gastos em segurança um indivíduo fizer, mais seguro estará em sociedade, além de esvaziar os espaços públicos (o que dificulta de forma significativa a efetivação de um modelo que se considere como democrático clássico), segrega a população dentro de suas esferas econômicas e gera um grande lucro paralelo.

A violência policial representa um problema de direitos humanos no Brasil, em especial no Rio de Janeiro. Não há dados disponíveis sobre mortes ocorridas durante operações policiais nos anos 1994 e 1995. A partir de 1998, é que a Secretaria de Segurança

\footnotetext{
${ }^{3}$ Art. 144. A segurança pública, dever do Estado, direito e responsabilidade de todos, é exercida para a preservação da ordem pública e da incolumidade das pessoas e do patrimônio, através dos seguintes órgãos: I polícia federal; II - polícia rodoviária federal; III - polícia ferroviária federal; IV - polícias civis; V - polícias militares e corpos de bombeiros militares.
} 
Pública do Rio de Janeiro começou a compilar essas estatísticas. Em 1998, 397 pessoas morreram por ação da polícia nesse Estado; em 2007, a cifra chegou a 1.330. Em 2014, houve 584 vítimas letais de intervenções policiais e, em 2015, esse número aumentou para $645^{4}$.

Entre as vítimas fatais de violência policial, estima-se uma predominância de jovens, negros, pobres e desarmados. Segundo dados oficiais, os homicídios são hoje a principal causa de morte de jovens de 15 a 29 anos no Brasil, e atingem especialmente jovens negros do sexo masculino, moradores das periferias e áreas metropolitanas dos centros urbanos. Dados do SIM/Datasus do Ministério da Saúde mostram que mais da metade dos 56.337 mortos por homicídios, em 2012, no Brasil, eram jovens (30.072, equivalente a 53,37\%), dos quais $77,0 \%$ negros (pretos e mulatos) e 93,30\% do sexo masculino. No Rio de Janeiro, aproximadamente 65\% das pessoas que morreram em 2015 são negras (negros e mulatos). No Estado do Rio de Janeiro, estudos mostram que a oportunidade de um jovem negro de morrer por ação da polícia é quase 2,5 vezes maior do que a de um jovem branco ${ }^{5}$.

Nesse panorama, é imprescindível entender como a polícia é protetora de Direitos Humanos, se ao mesmo tempo, é a violadora de Direitos Humanos? A forma de governança e a estrutura policial estão compatíveis com um Estado democrático de Direito ou são conceitos antagônicos?

Dessa forma, a partir da condenação brasileira realizada pela Corte Interamericana de Direitos Humanos (CorteIDH), em 2017, pela chacina ocorrida na Favela Nova Brasília, o presente artigo tem como objetivo analisar em que medida a estrutura policial pode ser democrática a fim de garantir a proteção dos Direitos Humanos ou se esta somente representa uma forma de poder em si mesmo?

Nesse sentido, o artigo irá se dividir em duas partes, uma primeira descritiva, a partir de uma análise jurisprudencial, em que será detalhado os fatos do caso Favela Nova Brasília e os argumentos utilizados pela CorteIDH para responsabilizar internacionalmente o Estado Brasileiro por violação de Direitos Humanos; e uma segunda análitica, utilizando-se de uma metodologia de estudo de argumentos doutrinários, em que será realizado uma análise crítica dos institutos "governança" "polícia" para verificar o que fundamenta a estrutura atual da polícia brasileira e se está em compatibilidade com um Estado protetor de Direitos Humanos.

\footnotetext{
${ }^{4}$ Fórum Brasileiro de Segurança Pública, Anuário Brasileiro de Segurança Pública 2015. São Paulo, 2015 (expediente de prova, folhas 14344 e 14354), e Dados do Instituto de Segurança Pública apresentados pelo Estado em suas Alegações Finais do Caso Favela Nova Brasília (2017).

${ }^{5}$ Idem.
} 


\section{O CASO FAVELA NOVA BRASÍLIA (2017)}

Na manhã do dia 18 de outubro de 1994, uma incursão policial foi realizada na Favela Nova Brasília por um grupo de 40 a 80 policiais civis e militares de várias delegacias da cidade do Rio de Janeiro. Durante a operação, os policiais invadiram pelo menos cinco casas, começaram a disparar contra os ocupantes e levar os corpos cobertos por cobertores, à praça principal da comunidade; detendo ocupantes para levá-los, e posteriormente, privá-los da vida e depositar seus corpos na mesma praça. Em duas das casas invadidas, os policiais interrogaram e cometeram atos de violência sexual contra três jovens, duas das quais eram crianças. Nessa operação, somente 28 policiais foram identificados.

No ano seguinte, no amanhecer do dia 8 de maio, um grupo de 14 policiais civis entrou na Favela Nova Brasília, com o apoio de dois helicópteros. A operação tinha como objetivo deter um carregamento ilegal de armas que seria entregue na localidade. Como resultado dessa incursão policial, três policiais foram feridos e 13 homens da comunidade foram mortos. Os laudos de investigação foram inconclusivos.

Em novembro do mesmo ano, uma petição inicial foi apresentada à Comissão Interamericana (CIDH) pelo Centro pela Justiça e o Direito Internacional (CEJIL). Em 19 de maio de 2015, a CIDH, diante do insucesso de uma solução amigável, apresentou a demanda junto à CorteIDH.

De acordo com a CIDH, o caso se refere às falhas e à demora na investigação e punição dos responsáveis pelas supostas “execuções extrajudiciais de 26 pessoas no âmbito das incursões policiais feitas pela Polícia Civil do Rio de Janeiro em 18 de outubro de 1994 e em 8 de maio de 1995 na Favela Nova Brasília”. O Estado brasileiro alegou que essas mortes foram justificadas pelas autoridades policiais mediante o levantamento de "atas de resistência à prisão".

Assim, em 16 de fevereiro de 2017, a CorteIDH considerou o Estado brasileiro responsável pela violação do direito às garantias judiciais de independência e imparcialidade da investigação, devida diligência e prazo razoável, estabelecidas no artigo 8.1 e 1.1 da Convenção Americana sobre Direitos Humanos (CADH), pois o efeito dos "autos de resistência à prisão" impactou toda a investigação da chacina, com consequências que 
perduraram ao longo do tempo, e que foram determinantes para a falta de devida diligência nas investigações (CORTEIDH, Caso Favela Nova Brasília Vs. Brasil, 2017).

A esse respeito, a CorteIDH identificou que em várias peritagens e declarações testemunhais anexadas ao caso, bem como a Defensoria Pública do Estado de São Paulo destacou em seu escrito de amicus curiae, mostraram que no Brasil tornou-se uma prática habitual em que os relatórios sobre mortes ocasionadas pela polícia se registrem como "resistência seguida de morte", e que no Rio de Janeiro se use a expressão "auto de resistência” para referir-se ao mesmo fato. De acordo com a Defensoria Pública, esse é o cenário ideal para os agentes que pretendem dar aspecto de legalidade às execuções sumárias que praticam (CORTEIDH, Caso Favela Nova Brasília Vs. Brasil, 2017).

O registro das execuções como "resistência à prisão" tinha um claro efeito nas investigações, na gravidade com que se assumiam os fatos e na importância que se atribuía à identificação e punição dos responsáveis. Além disso, a falta de independência concreta dos investigadores torna evidente a sua relação direta com os homicidas, suas ações tendenciosas e parciais e a excessiva morosidade dos procedimentos. A polícia civil foi incapaz de realizar as mínimas diligências necessárias para estabelecer a verdade sobre o ocorrido e instruir o processo penal contra os homicidas. Nesse caso, a Corte IDH destacou uma série de alertas a respeito da seriedade das condutas adotadas pelos agentes policiais, como as conclusões da Comissão Especial de Sindicância e, posteriormente, a intervenção do Ministério Público, em 2013. Sem prejuízo do exposto, essas ações foram demasiado tímidas para superar as falhas apresentadas de 18 de outubro de 1994 a março de 2013 (CORTEIDH, Caso Favela Nova Brasília Vs. Brasil, 2017).

Além disso, a CorteIDH também considerou que o Estado brasileiro é responsável pela violação do direito à proteção judicial, previsto no artigo 25 da $\mathrm{CADH}$, em relação aos artigos 1.1 e 2 do mesmo instrumento; pela violação dos direitos à proteção judicial e às garantias judiciais, previstas nos artigos 25 e 8.1 da CADH, e os artigos 1 , 6 e 8 da Convenção Interamericana para Prevenir e Punir a Tortura, bem como o artigo 7 da Convenção Belém do Pará; e pela violação do direito à integridade pessoal, previsto no artigo 5.1 da CADH (CORTEIDH, Caso Favela Nova Brasília Vs. Brasil, 2017).

Por fim, a CorteIDH determinou como medidas de reparação às vítimas, obrigação de investigar, o Estado deverá conduzir eficazmente a investigação em curso sobre os fatos relacionados com as mortes ocorridas na incursão de 1994, com a devida diligência e em 
prazo razoável; reabilitação, o Estado deve oferecer, gratuitamente, por meio de suas instituições especializadas de saúde, e de forma imediata, adequada e efetiva, o tratamento psicológico e psiquiátrico de que as vítimas necessitem, após o consentimento fundamentado e pelo tempo que seja necessário, inclusive com o fornecimento gratuito de medicamentos; medidas de satisfação, a publicação da sentença e a realização de um ato de reconhecimento de responsabilidade internacional, em relação aos fatos do presente caso e sua posterior investigação; além de indenização compensatória por danos materiais e morais.

Como garantias de não repetição, a CorteIDH determinou que o Estado deve dar prosseguimento às ações desenvolvidas e implemente, em prazo razoável, um programa ou curso permanente e obrigatório sobre atendimento a mulheres vítimas de estupro, destinado a todos os níveis hierárquicos das Polícias Civil e Militar do Rio de Janeiro e a funcionários de atendimento de saúde. Além disso, que o Estado adote as medidas legislativas, ou de outra natureza, necessárias para permitir que as vítimas de delitos ou seus familiares participem de maneira formal e efetiva da investigação criminal realizada pela polícia ou pelo Ministério Público, sem prejuízo da necessidade de reserva legal ou confidencialidade desses procedimentos.

Até o fechamento deste artigo, o Estado brasileiro somente cumpriu com a obrigação de publicação da sentença em português.

\section{2 É POSSÍVEL GOVERNAR COM A POLÍCIA?}

A partir da análise do caso Favela Nova Brasília (2017), é possível constatar um panorama antagônico e violador de garantias individuais, as fronteiras entre público e privado ganham novas delimitações e horizontes. Assim, entender a forma de governança (e governança da polícia) em tal panorama exige um conhecimento atual que compreenda as desenvolturas políticas e sociais dos atores que a completam e que incrementam suas exigências e emergências, formando a agenda deste setor.

Inicialmente, importante verificarmos o que poderia ser considerado como governança. Normalmente, tal estrutura é conceituada como uma agenda política direcionada para determinado objetivo (MUNIZ, 2009, p. 8). Tal conceituação nos apresenta uma visão geral, contudo, compreender precisamente o que seria este instituto, quais as nuances que o integram e as limitações que impõe, é tarefa de grande dificuldade. 
Muniz destaca o risco que se apresenta ao tentar definir a governança, principalmente quando se pondera a maneira como este acontecimento operaria e poderia ser compreendido como um fenômeno empírico, mediante as diferentes práticas de governança encontradas em diferentes instituições, em diversos contextos, mesmo como uma agenda de transformação nas mais diversas realidades $(2009$, p. 8).

Infere-se, então, que poderão existir a mesma quantidade de definições para governança, quanto práticas que tais institutos tentam concretizar. Pode-se encaixar em várias ações que demonstrem alguma dinâmica de comando ou direcionamento de ações com conotação pública em busca de objetivos da coletividade.

Pela amplitude que uma compreensão de espaço de tomada de poder detém, o termo governança poderá ser utilizado em diversas áreas públicas, alterando apenas o foco que se busca com aquela prática específica. Conforme Muniz defende, o termo governança vinculase ao reconhecimento de instâncias de produção de governo por diversos atores: o Estado e suas instituições, as organizações privadas, com e sem fins lucrativos, a sociedade civil (atores coletivos e individuais); e em diversos níveis de aplicação: dentro e fora do Estado, transnacional, internacional, nacional e localmente (2009, p. 9).

A governança seria formada por diferentes esferas de pactuação, com diferentes temporalidades, abrindo mão de instrumentalidades diferentes. Lida com estes elementos e constrangimentos em cada momento, considerando as ambições e possibilidades de governo diante das premissas ou urgências do presente. A governança se faz em um conjunto de possíveis influências, atuando simultaneamente em diversas direções, instâncias e contextos, chegando ao resultado que se revela possível. Pode se ter, assim, que a melhor definição de governança seria uma nova forma de se visualizar a expressão "a arte da política", uma vez que ambas remeteriam a mesma questão: em um governo se faz (governança ou arte da política) o que é possível de ser feito (MUNIZ, 2009, p. 15).

Percebe-se que a complexidade do termo governança é constituída pela série de interconexões que são realizadas entre os mais variados aspectos da existência política. Consideram-se diversas agendas de acordo com o que é possível e útil de ser feito em cada momento, em cada economia e em cada território.

Quando inserimos a democracia neste debate, pode-se questionar de que forma a governança se posicionaria frente à polícia neste modelo em um território democrático. É comum esperar que as atitudes governamentais sejam orientadas por princípios de legalidade, 
boa fé e (sobretudo) a legitimidade democrática, contidos no emaranhado de leis em vigor, advindas de um pacto normativo constitucional que direcionaria os agentes a tomar atitudes diária voltadas a um sentido único e pré-determinado.

Ao observar a forma como tais decisões vêm e são impostas à polícia, percebemos o que Muniz denomina de "governança de polícia", ou seja, a arte de política no exercício do governo pelo uso da polícia, propriamente dita, voltada para determinados fins, tendo como embasamento a reprodução autorizada e legal de obediência ao pacto político com certos meios e de determinados modos.

Alguns autores defendem conceituações que seguem um molde de polícia considerada como uma instituição autorizada pela lei a fazer com que esta seja cumprida em sociedade. Tal viés é comumente apresentado como sendo algo autorizado pela norma constitucional e funciona em função da sua concretização. Como exemplo, podemos citar Bayley. Para o autor, a única característica exclusiva da polícia seria a concessão do uso da força física na busca pela regularização das relações interpessoais na comunidade pautada em um conteúdo normativo autorizador. Para este, a polícia seria a união de três atribuições características, quais sejam: fazer; lidar; e tomar decisões ao se deparar com as situações concretas (2002, p. 117-119).

Goldstein, ainda, defende a complexidade que envolve a tentativa de compreensão do que seria a polícia, representando não apenas um degrau para sistema de justiça criminal, mas também a união de diversas outras finalidades, as quais muitas passariam bem distante da ideia de combater o crime (2003, p. 39).

Monjardet define a polícia como sendo uma instituição encarregada da função de deter e mobilizar os recursos de força decisivos, visando o objetivo de garantir ao poder o domínio ou a regulação do emprego da força dentro das relações sociais (2012, p.27).

Tais visões não são uníssonas na compreensão do que poderia ser compreendido como polícia. Contudo, encontramos em comum o fato de acreditarem na legitimidade derivada da lei da atual estrutura frente a complexidade social, utilizando-se de meios legislativos do estado para a realização da contenção de parcelas da sociedade dentro do seu convívio diário.

Nesse sentido, a democracia ocuparia um papel de pressuposto, pois seria usada como fonte de legitimidade para que se possa ter uma resolução ao enforcement previamente concordado. 
Ao vislumbrar tal prisma, percebe-se que a polícia ao receber tal mandato, lida diretamente com a forma que vai coexistir com a expectativa da sociedade que espera uma atuação policial pautada na produção de alternativas de submissão e respaldo subordinado a um império de normas, dispositivos democráticos de controle e determinador de limitações necessárias.

Ao mesmo tempo, a democracia consegue representar uma utopia quanto ao marco de onde se quer chegar e o local de onde se intenta partir, quando tratamos da atuação policial. Com essa limitação e pressuposto que se autoriza a concessão de um mandato policial. Nas palavras de Muniz: "Trata-se de dispor da certeza de um enformecent que permita o próprio funcionamento democrático da policy, que sustente a paz social, as leis, os direitos e garantias, e tudo mais que corresponde aos termos constitucionais pactuados" (MUNIZ, 2009, p. 16).

Ao analisar esta base de pressupostos e finalidades de atuação, pode-se perceber que quando inserimos a polícia neste contexto, um novo viés se apresenta, qual seja: o fato da polícia não poder ser reduzida a uma certa quantidade de atuações e procedimentos previamente estabelecidas em manuais e regramentos internos e estatais. Isso se dá frente a complexidade de relacionamentos e incorrências para as quais os policiais são chamados a agir diariamente. Não haveria como prever todos os possíveis inter-relacionamentos que uma sociedade poderia desenvolver, bem como delimitar uma resposta estatal (mediante criação legislativa) para todos estes. Nem toda a criação legislativa ou experiência na atuação quanto policial seria capaz de substituir o peso que a decisão política tem sobre a instituição policial durante o exercício de certo governo.

A relação entre o governo vigente e o direcionamento de atuação e estruturação da instituição policial estão diretamente conectados em uma sociedade democrática. Ponderando sobre esta estreita vinculação entre a atuação policial em sociedade e as agendas de governança estatais, Muniz leciona que:

\footnotetext{
A decisão política, o rumo da governança, não é o resultado somatório cumulativo da enunciação e nem mesmo da adesão ao que se apresentam como boas práticas. Ao contrário, é a decisão política, é a governança, que decide apor, manter, ou retirar de uma prática o qualificativo de "boa" (2009, p. 16).
}

Ao fazer tais constatações, é possível perceber que a atuação policial não será pautada apenas em ditames objetivos e restritos previamente dispostos em regulamentos. Tampouco 
será reduzida a fazer o que a lei determina. Não será realizada de forma aleatória a seleção de policiamentos, pelo contrário, exige-se que a demanda diária da polícia seja voltada a um fim "necessário" à sociedade e aos moldes do governo. Dessa forma, haverá uma grande influência de um poder subjetivo baseado em uma agenda econômica e de manutenção das massas sociais.

Nesse sentido, Rancière leciona que a ideia do que poderia ser considerada como política seria constituída pela conexão entre dois processos heterogêneos, quais sejam: a polícia e a igualdade.

O primeiro processo seria o que o autor denomina de "polícia". Neste, haveria a indução da criação de um consenso comunitário, por meio do qual seria disseminada a distribuição dos lugares, hierarquias e funções, relembrando a ideia de Foucault de disciplinarização dos corpos ou de uma sociedade de vigilância. Destaca-se, aqui, que essa forma de distribuição de espaços e identidades seria uma via de enquadrar o visível (e o invisível) comum, a isso o autor denominou de "partilha do sensível".

Por sua vez, o segundo processo que fundaria o político seria aquele pertencente à "igualdade". Este deveria ser compreendido como uma reunião de técnicas orientadas pela suposição de que todos são iguais e detentores de idêntica capacidade para compreender e perceber tal presunção. Para Rancière, a denominação apropriada para este conjunto de práticas deve ser "emancipação".

O que existiria, então, seriam duas estruturas diferentes. A primeira apenas reconheceria a existência da regulamentação e caracterização de movimentações e fluxos, impondo uma lógica de caracterização e concordância. Essa seria responsável pela manutenção dos indivíduos em seus respectivos postos dentro da coletividade.

Enquanto a segunda versaria sua inteligência de forma desincorporada apenas sobre a igualdade e suas formas de exteriorização no mundo pelos sujeitos políticos, se revelando como um dissenso que buscaria retirar os indivíduos de seus lugares determinados pela estrutura anterior. O universo político, então, seria compreendido mediante esta dúplice forma de gerenciar a coletividade.

Nesse sentido, leciona que: "Há modelos de governo e práticas de autoridade baseados em tal ou tal distribuição de lugares e competências. Essa é a lógica que propus pensar sob o termo de polícia”"(2014, p. 63). 
Necessário distinguir que, para Rancière, a intervenção democrática seria uma forma de acabar com todos os padrões que foram previamente estabelecidos por um modelo desigual de sociedade. Neste trabalho, vislumbramos a democracia como marco utópico de saída e de chegada dentro de um determinado contexto de governança e de constituição social.

A conexão entre polícia e a forma de governança, então, extravasa a imposição normativa ou o pressuposto de atuações pautadas em limitações dispostas em lei, traz também uma profundidade relacionada a sua necessidade social e política, uma vez ser depositada nesta instituição a responsabilidade pela manipulação da massa de acordo com uma agenda política e econômica que deveria estar previamente definida, algo que caracterizaria um governo como uma forma de governança legitimamente constituída. Dessa forma, seria possível afirmar que a governança de polícia recai concomitantemente sobre as finalidades, as formas de atuação e a existência da polícia como um todo.

Com a leitura apresentada pela obra de Rancière, podemos perceber que a visão apresentada por autores mais liberais sobre a polícia, normalmente, deposita na instituição policial certa obrigação impositiva de fazer valer o texto legal. Na tentativa de não visualizar essa determinação cega dos ditames normativos como um fim em si mesmo, é possível perceber que (não aleatoriamente) a imputação de tal atuação com a finalidade narrada auxilia a manutenção de cada parcela social no seu espaço social (cárcere, favelas ou condomínios de luxo).

Quando tais atuações passam a ser direcionadas com um bojo normativo consistente e formalmente legítimo podemos perceber de onde vem a autorização para que a prática se dê por um viés tão seletivo e controlador e diretamente violador de direitos.

A intervenção subjetiva da governança na atuação policial, dentro de uma atmosfera democrática legítima, pode receber questionamentos quanto a atuação dos agentes policiais em práticas diárias, bem como quanto a tentativa de verificar se a criação de políticas públicas que insiram as polícias na sua esfera de abrangência seriam (ou não) adesivas a uma democracia. Ainda, indagam-se quantas violações a direitos e percepções distintas da mesma realidade social seriam necessárias de serem verificadas para que se torne possível perceber certa estruturação de adesão à democracia entre as mais diferentes polícias.

Questiona-se qual o limite de aceitação acerca das violações compreendidas como interiores (e por isso necessárias) dentro de um modelo de governança previamente constituído. Até onde a governança perderia o controle ou dominaria a democracia, 
estaríamos semeando a desgovernança ou uma forma de governança absoluta e ilimitada? Casos como a chacina da Favela Nova Brasília poderia ser vista como uma falha pontual ou a reprodução de um projeto de governo?

$\mathrm{Na}$ tentativa de verificar o quanto de anterioridade e ambição democrática seriam depositados sobre o todo da polícia que se teria a governança de polícia. Nas palavras de Muniz:

\begin{abstract}
Numa democracia, a governança de polícia pressupõe a existência de instâncias autorizativas e mecanismos de controle do governo pela policy. Estas instâncias e mecanismos configuram os espaços de construção de legitimidade e de legitimação da ação de governo e, portanto, da decisão policial. Constituem arranjos diferenciados de participação e de controle popular que se fazem presentes em maior ou menor grau na pactuação constitucional; na dinâmica contextual do relacionamento com a polícia, ou seja, no cotidiano da fabricação da ordem social; na identificação e busca das ambições da suposta cidadania (2009, p. 18).
\end{abstract}

Nesse sentido, tal forma de governança se aceita e propagada sem uma definição positiva do que efetivamente seria sua atuação democrática poderia conduzir a sociedade a técnicas não autorizadas de padronização social e de manutenção de parcelas em seus respectivos espaços econômicos sociais, calando vozes e desestimulando práticas democráticas que estimulem a participação popular (como por exemplo o encontro em praças públicas para debate das questões sociais, conforme modelo de democracia clássica apresentado por Aristóteles (2011)).

Em uma democracia além da legitimidade concedida pelo modelo de anterioridade normativa exigido e estandardizado em seus meios criativos, temos, também, a presunção de que existam regras do jogo previamente definidas a serem postas como a finalidade principal do enforcement que norteariam a atuação do policiamento no cotidiano, bem como o modo como a polícia se estrutura como um todo.

Muniz leciona que todas as leis derivam de acordos e negociações entre interesses oponíveis, logo, toda norma seria a instrumentalidade de um acordo, uma instrumentalidade da política. Por tal fato, as leis se alterariam de acordo com embates políticos entre os diversos interesses presentes em determinada policy. Para a sua aplicação, haveria certa inércia interpretativa e resiliência diante da política que a própria estrutura política delegou. Nesse meio, as garantias fundamentais seriam reflexos das ambições mais longevas de certo pacto no interior de determinada policy, em certo contexto temporal e histórico (2009, p. 20).

Observando a situação apontada, quando vislumbramos um molde democrático reduzido a períodos cívicos, onde a intervenção popular é chamada a agir de tempos em 
tempos certos, podemos ser conduzidos a um sistema de manipulação das regras do jogo e de condução à conveniência de um governo temporal. Explica-se, aquele que detiver o poder para criar leis, o faz mediante negociações escusas dentro de um contexto de interesses próprios, tudo revestido da legalidade que uma versão reduzida de democracia (diminuída à representação) concede para atuação da política no momento de colocar este projeto de governo em prática.

Não se nega que a existência legislativa fornece estabilidade de comportamentos, padronização de atuações sociais e institucionalização das relações de poder. Mas verifica-se que estas não se aplicam de forma equitativa, nem para a população de forma geral, nem entre os próprios agentes do estado, existindo para servir, enquanto forem úteis, a determinados fins políticos certos (LUSTGARTEN, 1986, p. 22).

Ao considerar que a governança de polícia apresentaria suas faces (principalmente por meio da atuação de seus personagens junto à população e os conflitos diários), mediante a tentativa de garantir a conexão entre as práticas policiais e a decisão política dentro dos padrões normativos democráticos previamente delimitados e repassados aos integrantes da corporação.

Nas palavras de Muniz, tenta-se relacionar em uma mesma estrutura a ação governamental voltada para determinada agenda e os resultados consequenciais policiais. Seria eleito, no interior da polícia, o que seria preciso ser contido para que se possa compreender o total do conteúdo de sua práxis de maneira que se possa governá-la. Isso significaria que qualquer governança de polícia expressaria um juízo de razoabilidade quanto o que poderia ser sabido para que se consiga efetivamente governar, bem como o que se busca controlar para saber $(2009$, p. 22).

O conhecimento e a detenção do poder serão substanciais para o exercício de uma governança capaz de implantar e manter as suas regras do jogo, direcionadas a agendas previamente negociadas que se busca seguir em determinado território. Quanto mais se consegue prever os conflitos e dominá-los (ou pelo menos reduzir seus potenciais danos) maior o controle exercido sobre a população. Ressalta-se que a autoridade exercida nunca será total sobre todas os pontos das mazelas e complexidades sociais, mas dentre toda essa teia de conflitos, são selecionados aqueles úteis para corroborar a agenda previamente determinada ou para unir a população conta um inimigo em comum. 
Dentro desse contexto de controle, existe um viés importante para este trabalho, àquele que permite que o governo governe a polícia, derivando de uma medida de razoabilidade.

A razoabilidade defendida seria o produto de determinado cálculo político que buscaria fornecer certa legitimidade para que exista respaldo suficiente para sustentar arranjos de poder. É possível inferir, então, que a razoabilidade se coloca sobre uma padronização geral direcionada para certo processo político, materializando as finalidades de determinado governo.

Nesse contexto, destaca-se que afirmar que determinada atuação é razoável, não significa defender que esta é democrática. Para que seja possível conectar estas é necessário que a razoabilidade mantenha sua atuação dentro de limites éticos delimitados previamente, que estimulem a participação popular e a expressão da sociedade em vias legítimas.

Pelo exposto, percebe-se que mediante a negociação da agenda de cada governo, o direcionamento da polícia se altera. A questão que se coloca é de que forma isso poderia ser considerado como legítimo dentro de uma sociedade considerada como democrática. Verificou-se que a razoabilidade utilizada como possível resposta, assim como as autorizações concedidas aos agente estatais, encontram-se pautadas por direcionamentos alcançados por negociações políticas.

Muniz adverte que a legalidade tem papel essencial na possibilidade de uma governança de polícia, não sendo claros seus limites. A autora defende que o poder coercitivo (como perspectiva do que é essencial para o trabalho policial) e o uso discricionário desse poder (como reconhecimento da natureza política da atividade policial e do potencial emancipatório deste meio de força) seriam como dois qualificativos de partida para compreensão do governo de polícia (2009, p. 24).

Nesse sentido, alerta que existem dois erros quando se analisa a polícia. O primeiro deles seria a confiança que se deposita na ideia de que o "verdadeiro trabalho da polícia" seria o respaldo da lei pelo controle do Judiciário, pois ignoraria a natureza post-facto de tudo que se pode querer ter como Judiciário, bem como não ponderaria sobre as temporalidades concorrentes que existiriam na sua atuação, alimentando, assim, a seletividade no agir e nas formas de atuar, por consequência, no que seria registrado nos relatórios. O controle da lei, então, se daria apenas sobre pequenos desvios, mas omitiria o uso do poder coercitivo com a finalidade de reprimir, dissuadir e qualquer função de atuação preventiva (2009, p. 25). 
Com as contribuições da autora, podemos perceber que o controle da polícia pela lei ou a utilização de uma conceituação de polícia conectada com a submissão normativa e uma atuação determinada pelo texto normativo, acaba sendo uma falácia em relação a resultados democraticamente seguros.

A atuação policial reproduz um molde de interesses temporais previamente determinados por jogos políticos de negociação de interesses. Dessa forma, a reprodução de um modelo democrático que estimule a participação popular e a efetivação de princípios constitucionais (como por exemplo a igualdade), acabam tendo sua aplicação na sociedade dificultada frente a discricionariedade que o poder coercitivo detém.

Conforme assevera Muniz, não seria necessário verificar qual governança de polícia a accountability permite, mas qual accountability se deve ter para que se possa considerar que há uma governança de polícia. Tal análise seria necessária para que se possa observar o quanto a polícia seria adesiva em relação a uma democracia (2009, p. 102).

Nesse sentido, podemos analisar as lições trazidas por Lustgarten (1986) .O autor verifica três espaços onde haveria acesso e solução de controle para tal dinâmica de poder. Inicialmente realiza uma análise sobre as estruturas e capacitações, após é verificada a percepção sobre as alocações e prioridades, por último, as práticas estabelecidas de seletividade e enforcement.

Quanto ao primeiro, a estrutura fornecida pelo público e a capacitação dos agentes integradores de tal estrutura seria essencial para delimitar quais os limites (ou a ausência deles) de atuação enquanto detentores de um mandato legítimo.

Governar a polícia, para o autor, iniciaria com a definição clara e nem um pouco aleatória do que esta pode (ou não) ser capaz de fazer perante a população e sua própria constituição interna. Interessante observar, então, que tudo o que versa sobre a polícia é decidido e delimitado por uma série de negociações e decisões políticas, mas não pela própria polícia interessada.

Logo, a verificação da estrutura e de sua capacitação seria a primeira forma de controlar a polícia por parte do governo, fazendo com que está jamais consiga sua emancipação de uma forma legítima perante a policy.

Para o autor, tal controle realizaria uma tutela sobre a autonomia da discricionariedade, pois forneceria certa quantidade de possibilidades previamente 
determinadas e limitadas, além da ausência de caminhos para questionar tais fronteiras de agir impostas.

Percebe-se, então, que a dita discricionariedade policial não seria ampla e irrestritamente considerada sobre aquilo que o indivíduo ocupante da farda pensa naquele dia, mas seria uma discricionariedade vinculada a uma gama de atuações previamente autorizadas como sendo de interesse da manutenção da policy. Controla-se o cerne da autonomia de governança policial, fazendo com que a governança de polícia estabeleça todos os parâmetros para que seja gerida esta primeira.

Por segundo, Lustgarten verifica que a alocação e as prioridades no uso dos recursos policiais na formação de certas estruturas e capacitações disponibilizam deveria ser visto como uma questão de governança de polícia.

A definição de como os recursos internos seriam gastos de acordo com as finalidades impostas por tal estrutura política, fariam com que a alocação e as prioridade expressassem escolhas que sopesassem alternativas políticas e policiais sobre de que maneira a polícia deveria/poderia disponibilizar sua capacidade no exercício de sua função.

Percebe-se que a alocação de recursos para tais estruturas diz bastante sobre a forma política com a qual determinada governança de polícia se solidifica, uma vez que tais benesses seriam concedidas com uma finalidade previamente determinada pela agência de quem detém o mandato eletivo. Não haveria, então, uma gestão autônoma por parte dos recursos disponibilizados, mas pela interpretação feita da obra de Lustgarten haveria uma gestão previamente orientada e direcionada dos recursos policiais de acordo com o que se espera que a polícia faça na sua atuação diária.

Interessante observar que, conforme advertido por Muniz, a determinação da atuação diária policial se altera com o tempo (2009, p. 42). Logo, quem detém o poder poderia iniciar certa atuação policial e, no curso, a depender dos resultados verificados ou dos interesses motivadores, alterar tal disposição para esta ou para uma certa quantidade de circunstâncias que sejam semelhantes. Tal atuação, poderia se mostrar como uma verdadeira arma antidemocrática em uma atuação direcionada para um viés extremamente seletivo manejado por quem governar a polícia.

Nesse sentido, haveria uma gestão direcionada sobre tudo que dispõe acerca da estruturação e delimitação de prioridades da polícia, o que poderia ou não ser feito, impedindo qualquer possibilidade de emancipação. 
Quando se pensa sobre a discricionariedade existente, se verifica a permissão concedida pela forma de governo em relação a tal atuação. Apesar do que se pode pensar, a atuação discricionária concedida aos policiais está situada dentro das possibilidades que seriam mais interessantes de acontecerem dentro de uma gama de possibilidades disponibilizadas pela forma de governança em gestão.

Por fim, o autor analisa as práticas estabelecidas de seletividade do enforcement. Neste, atesta ser valorizada a forma como a polícia adota sozinha os encaminhamentos gerais. Considera que, na atuação rotineira, a polícia escolherá determinadas orientações que deverão ou não ser apresentadas ao público, como se houvesse uma validação interna das ordens gerais emanadas pela forma de governança.

Neste terceiro passo de análise, a figura do policial individualmente considerado ganha importância, pois o seu sopesar e a sua submissão (total ou parcial) a estrutura hierarquizada policial seriam as possibilidades de consolidar os ditames de negociações políticas quase inatingíveis para estas pessoas nestas funções.

Pelo exposto, percebe-se que a atuação policial baseada na forma como é utilizada, poderia ser verificada como uma forma de intervenção do Estado no âmbito privado da população, tanto no sentido de manutenção destes indivíduos em suas parcelas sociais, como coberta por um viés onde aqueles excedentes ou não consumidores deveriam ser excluídos da sociedade, de acordo com uma agenda previamente selecionada que não aceita contraditórios e não tem atuações aleatórias em relação a seletividade social.

Nesse sentido, o papel da polícia é de ser obediente e estritamente submisso à preceitos determinados que lhe são impostos, tanto como forma de submissão, como revestido de uma atuação de controle mediante metas definidas e repassadas.

Haveria, então, íntima relação entre o que seria compreendido como governança de polícia e uma governança policial. Para melhor elucidar, Muniz explica que:

Pode-se delinear a governança de polícia como o governo em ato que se relaciona,
em diferentes instâncias deliberadamente escolhidas, com, e sobre, a governança
policial. Só assim se pode ter uma governança de polícia capaz de governar o todo
da polícia sem se perder na irrazoabilidade de buscar governar tudo na polícia (2009,
p. 109).

Questiona-se sobre se determinado governo, ao delimitar certa política com a legitimidade da policy, não se utiliza da governança policial para entrar em terrenos 
constitucionalmente protegidos (como por exemplo o da privacidade), fazendo isso de forma selecionada sobre determinadas parcelas sociais previamente delimitadas.

Em conclusão, percebe-se que tais violências policiais como a que aconteceu na chacina da Favela Nova Brasília, representam violências estruturais não completamente desconectadas em uma sociedade democrática, bem como que o ato de governar mediante atuações legítimas da polícia tem uma função seletiva de controle social com um fim bem específico. Ademais, a estrutura policial não deve ser vista como uma formação independente e desconectada de direcionamentos políticos, pelo contrário, configuraria-se em estrutura, atuação e ideologia como produtos de negociações políticas. Para tanto, tais direcionamentos não podem ser considerados como políticas engessadas, pelo contrário, versam sobre uma autonomia que se encontra em constante redefinição de finalidades e lucros e que se opera, sobretudo, como forma legitima de controlar a sociedade mediante intervenção justificada por uma utópica segurança normativa.

\section{CONSIDERAÇÕES FINAIS}

Conforme demonstrado, violências como as ocorridas na caso Favela Nova Brasília (2017) deveriam ser consideradas como inaceitáveis dentro de um Estado que se identifique na sua constituição como democrático e que deposite em seus agentes a confiança para a efetivação de direitos à população, e não a retirada destes.

As condenações internacionais, como à aplicada ao Brasil e aqui comentada, apenas atestam as violações que o país submete a sua população diariamente. No mesmo sentido, o descumprimento quase integral das penalidades apresentadas nesta decisão, demonstrariam um verdadeiro descaso com a efetivação de Direitos Humanos, assim como uma dupla violação de obrigações internacionais por descumprimento de sentença que elucida obrigações reparadoras de violações de Direitos Humanos.

O que tentou-se verificar nestas linhas é se tal desrespeito contínuo à legislação nacional e direcionamentos internacionais seria, de fato, um desvio na aplicação da norma por agentes desviantes internos (que poderiam ser, por exemplo, erroneamente conduzidos à satisfação de anseios individuais na ocupação de cargos públicos) ou se esta forma violenta, impositiva e militarizada de atuação pelo Estado brasileiro, mediante seus agentes policiais e a atual estrutura da polícia, além de muito bem conhecida e coordenada pelos governantes 
para assim agirem, utilizaria a aplicação da coerção e da violência como uma forma regular de governança pautada por uma busca pelo controle social, mediante uma exploração seletiva da população nacional.

Conforme foi demonstrado, o direcionamento da atividade policial em casos semelhantes ao caso Favela Nova Brasília (2017) pode ser considerados como uma forma de governo muito bem definida que, selecionando a população mediante um crivo de pobreza/riqueza atuaria de forma sumária, voltando-se a disseminar o medo a partir de uma violência institucional que tem como objetivo manter o controle da população e, principalmente, a dispersão de temores coletivos e a constante necessidade por segurança e proteção, quase como uma resposta automática.

Por fim, verificou-se que tais atuações seletivas e violadoras de direitos representam uma agenda de governo específica que assume a exploração e sofrimento de uma parcela economicamente desfavorecida para exercer um controle social nacional. Neste sentido, a polícia e a sua estrutura violenta representam uma instituição fundamental dentro desta estrutura violadora, dentro desta governança, pois enquanto agirem voltadas para ideologias e atuações resultantes de negociações políticas que selecionam os seres humanos que serão dignos de direitos e o que não os terão, jamais poderão emancipar-se de uma atuação voltada à efetiva proteção de Direitos Humanos.

\section{REFERÊNCIAS}

ARISTÓTELES. A política. Rio de Janeiro: Saraiva, 2011.

BAYLEY, David H. Padrões de Policiamento. São Paulo: ed.usp, 2002.

CORTE INTERAMERICANA DE DIREITOS HUMANOS. Caso Favela Nova Brasília Vs. Brasil. Sentença de mérito, reparações e custas de 16 de fevereiro de 2017. San José, Costa Rica, 2017.

DELUCHEY, Jean; BRITO, Michele. Tensões Contemporâneas da Repressão Criminal. São Paulo: Livraria do Advogado, 2013.

GOLDSTEIN, Herman. Policiando uma sociedade livre. São Paulo: ed. Usp, 2003.

LUSTGARTEN, Laurence. The governance of police. 1986. 
MARQUES NETO, Agostinho Ramalho. O Poder Judiciário na Perspectiva da sociedade democrática. O Juiz Cidadão. In Revista ANAMATRA. São Paulo, n. 21, p. 30-50, 1994.

MELOSSI, Dario e PAVARINI, Massimo. Cárcere e Fábrica (As origens do sistema penitenciário nos séculos XVI - XIX). Rio de Janeiro: Ed. Revan, 2006.

MONJARDET, Dominique. O que faz a polícia? São Paulo: ed. Usp, 2012.

MUNIZ, Jacqueline. PONCIONI, Paula. PROENÇA JÚNIOR, Domício. Da Governança de Polícia à Governança Policial: controlar para saber, saber para governar. Revista Brasileira de Segurança Pública, Ano 3 Edição 5, Ago/Set 2009.

RANCIERE, Jacques. Em los Bordes de lo politico. Escuela de Filosofia Universidad ACIS.

RANCIÈRE, Jacques. O Ódio à Democracia. São Paulo: Boitempo Editorial, 2014. 